\title{
PARATEXTS ACROSS PERIODS AND GENRES
}

